\title{
Role of hyaluronidase in Streptococcus intermedius biofilm
}

\author{
D. Pecharki, F. C. Petersen and A. Aa. Scheie \\ Department of Oral Biology, Faculty of Dentistry, University of Oslo, N0316 Oslo, Norway
}

Correspondence

D. Pecharki

ddasilva@odont.uio.no

Received 13 August 2007

Revised 20 November 2007

Accepted 14 December 2007

\begin{abstract}
Streptococcus intermedius is found in biofilms on teeth and as a commensal member of the gastrointestinal and urinary floras, but may also be associated with deep-seated purulent infections and infective endocarditis. $S$. intermedius produces hyaluronidase, an enzyme that breaks down hyaluronan (HA), a major component of the extracellular matrix of connective tissue. We investigated the involvement of hyaluronidase in $S$. intermedius biofilm formation and dispersal as well as adhesion to human cells. The hyaluronidase activity and expression of the hyl gene were higher in growth media supplemented with HA. Inactivation of the S. intermedius hyaluronidase resulted in a mutant that formed up to $31 \%$ more biofilm in media supplemented with HA. Hyaluronidase added to the medium caused dispersal of $S$. intermedius biofilm.

Adhesion to epithelial cells was similar in the wild-type and the hyaluronidase mutant. We concluded that hyaluronidase may be important for $S$. intermedius detachment from biofilms but not for adhesion to epithelial cells. The ability of $S$. intermedius to detach from the surface and to spread may be crucial in the pathogenicity of this micro-organism.
\end{abstract}

\section{INTRODUCTION}

Streptococcus intermedius is a commensal member of the human oral, gastrointestinal and urinary floras, but may also be associated with deep-seated purulent infections, particularly in the brain and liver (Claridge et al., 2001; Whiley et al., 1992). In the oral cavity, S. intermedius is mainly found in biofilms on teeth, but may be associated with periodontal disease and implantitis (Tanner et al., 1997). In subcutaneous abscesses induced by dental plaque in mice, S. intermedius was found in approximately $50 \%$ of the cases (Okayama et al., 2005). Like other oral streptococci, S. intermedius may be implicated as a causative agent of infective endocarditis (Gossling, 1988; Hamada \& Slade, 1980; Piscitelli et al., 1992; Whiley et al., 1992).

Hyaluronan (HA) is a major component of the extracellular matrix of connective tissue and is expressed by many cell types, including keratinocytes (Agren et al., 1997). In epithelial cells, HA may mediate the adherence of bacteria exhibiting HA-binding surface proteins (Aoki et al., 2004). HA is a high-molecular-mass polysaccharide, made up of alternating $\mathrm{N}$-acetylglucosamine and glucuronic acid residues linked by glycosidic bonds (Girish \& Kemparaju, 2007). HA has been suggested to support cell proliferation and migration during challenges like wounding and inflammation (Tammi et al., 2002). In the oral cavity HA is present in saliva (Pogrel et al., 1996), in the

Abbreviation: $\mathrm{HA}$, hyaluronan. epithelium of the oral mucosa (Tammi et al., 1990), and in gingival exudates from sites of chronic gingivitis (Last \& Embery, 1987). HA is also found in sites associated with S. intermedius purulent infections, including brain (Ruoslahti, 1996), heart (Camenisch et al., 2000) and liver tissues (Nyberg et al., 1988).

HA may be cleaved by bacterial hyaluronidase at the $\beta-1-4$ linkage, the products being unsaturated disaccharides (Hynes \& Walton, 2000). The main hyaluronidase function is claimed to be provision of bacterial nutrients by the enzymic depolymerization of HA (Starr \& Engleberg, 2006). The disaccharides produced may be transported and metabolized intracellularly. Another important hyaluronidase function is HA degradation in connective tissues, which may allow the spread of pathogens or toxins from an initial site of infection (Feldman et al., 2007; Starr \& Engleberg, 2006). Interestingly, the severity of gingivitis in young male adults correlated with their salivary hyaluronidase activity (Rovelstad et al., 1958). Among oral streptococci, only S. intermedius and Streptococcus constellatus produce hyaluronidase, with $S$. intermedius strains showing a higher frequency of enzymic activity (Takao, 2003). The $S$. intermedius hyaluronidase also breaks down chondroitin sulphate, although degradation rates are less than $8 \%$ of the rate with HA (Shain et al., 1996). The hyaluronidase in $S$. intermedius is closely related to that in Streptococcus pneumoniae, including conserved regions associated with carbohydrate binding, enzyme activity and cell wall anchoring domains (Takao, 2003). Most of the hyaluronidase activity is found in the culture 
supernatant (Homer et al., 1997). Production of bacterial hyaluronidase in the area of the gingival crevice may interrupt the integrity of the periodontal tissue by breaking down HA, leading to periodontal destruction and spread of toxins. The presence of the anchoring domains may also suggest a role for the enzyme on the bacterial cell surface.

In nature micro-organisms grow preferentially in highly specialized biofilm communities (Costerton et al., 1995). Biofilm formation is a dynamic process where extracellular polymers provide the matrix of densely aggregated surfaceadherent micro-organisms (Costerton et al., 1999). A wide range of factors may be important for biofilm integrity and stability, including bacterial surface proteins, bacterial enzymes, and amount and types of nutrients in the environment (Branda et al., 2005; Sutherland, 2001). HA present in saliva and connective tissue might serve as a source of nutrients or adhesion substrate and thereby affect biofilm formation. It is also possible that HA may form part of the complex extracellular polymer matrix of biofilms. Hyaluronidase might also be involved in biofilm formation through different mechanisms. While surface bound, hyaluronidase might function as an adhesin. Surface-bound and cell-free enzymes might influence nutrient availability, or promote detachment of cells from the biofilm. Several studies have shown the presence of hyaluronidase at sites of infection (Hashioka et al., 1994; Takao et al., 1997; Unsworth, 1989). However, little is known about the specific role of $\mathrm{HA}$ and bacterial hyaluronidase in biofilm formation and dispersal. The ability to express hyaluronidase and to form biofilms may be critical for the pathogenesis of $S$. intermedius. The aim of this study was therefore to investigate whether biofilm formation or dispersal, as well as adhesion to epithelial cells, may be affected by hyaluronidase.

\section{METHODS}

Bacterial strains and culture media. The S. intermedius strains used in this study were the type strain NCTC 11324 and its isogenic hyaluronidase mutant SI009 $\left(\mathrm{Hyl}^{-}\right.$, described below). The strains were stored at $-20{ }^{\circ} \mathrm{C}$ in brain heart infusion broth (Difco) supplemented with $15 \%(\mathrm{v} / \mathrm{v})$ glycerol.

Growth conditions. Growth rate in liquid culture was monitored in trypticase soy broth (TSB, Difco) supplemented or not with HA (1 $\mu \mathrm{g}$ $\mathrm{ml}^{-1}$, Sigma) or in minimal medium (MM) (Homer et al., 2001) supplemented with glucose $\left(1.8 \mathrm{mg} \mathrm{ml}^{-1}\right.$ ) or HA (up to $5 \mathrm{mg} \mathrm{ml}^{-1}$ ) as carbohydrate source. Bacterial cultures were incubated at $37{ }^{\circ} \mathrm{C}$ in a $5 \% \mathrm{CO}_{2}$ aerobic atmosphere. $\mathrm{OD}_{600}$ was measured at different time intervals until stationary phase.

Construction of the hyaluronidase-defective mutant. The $S$. intermedius hyaluronidase gene was inactivated by insertion duplication, using the streptococcal integration vector pSF151 (Tao et al., 1992). The hyaluronidase preliminary sequence information from $S$. intermedius UNS 35 was kindly provided by Dr Karen A. Homer, KCL, London. The forward primer FP062 (5'-CAGAATTCCAAGATGGCTCTTACATTGACC- $\left.3^{\prime}\right)$ and the reverse primer FP063 (5'ACTCTAGAGCGCGGCTTAAGTCCATTAATTC- $3^{\prime}$ ) were used to amplify a 207 bp region of the hyaluronidase gene. The amplicon and
pSF151 were digested with EcoRI and XbaI, ligated, and used to transform S. intermedius NCTC 11324. Transformation was conducted as previously described (Petersen et al., 2001). The transformants were selected by plating the cells on Todd-Hewitt broth agar plates containing $5 \%$ horse serum and kanamycin $(500 \mu \mathrm{g}$ $\mathrm{ml}^{-1}$ ). An isogenic mutant was randomly selected for further characterization and named SI009. The correct inactivation site was confirmed both by Southern hybridization with probes for PSF151 or $h y l$, and by DNA sequencing using the forward primer FP039 (5'AGCGGATAACAATTTCACACAGGA-3') corresponding to the distal region of pSF151 and the reverse primer FP063.

RNA isolation and real-time PCR. Total RNA from S. intermedius grown in TSB or in TSB supplemented with HA was extracted at various time points with the High Pure RNA isolation kit (Roche) according to the manufacturer's recommendation, except that the cells were incubated at $37{ }^{\circ} \mathrm{C}$ for $30 \mathrm{~min}$ in $100 \mu \mathrm{l}$ lysis buffer containing $20 \mathrm{mg}$ lysozyme $\mathrm{ml}^{-1}$ and $100 \mathrm{U}$ mutanolysin $\mathrm{ml}^{-1}$. DNase I was used during the RNA extraction to remove remaining DNA. RNA concentration was adjusted to $100 \mathrm{ng} \mathrm{ml}^{-1}$, and samples were stored at $-70{ }^{\circ} \mathrm{C}$ until use.

Complementary DNA templates were created from 50 ng RNA using the Transcriptor First Strand cDNA Synthesis kit (Roche), following the manufacturer's protocol. The primer pair FP112 (TGCTGAAAAAGTGCAACAGG) and FP113 (ATCAAGCCAAGCATTCCATC) was used to investigate $h y l$ expression by real-time PCR. To normalize the data, the primer pair FP116 (TGAAGAAGGTTTTCGGATCG) and FP117 (CGCTCGGGACCTACGTATTA) was used to amplify a sequence in the housekeeping $16 \mathrm{~S}$ rRNA gene. Real-time PCR was carried out in the ABI Prism 7700 detection system (Applied Biosystems) using qPCR Mastermix for SYBR Green I (Eurogentec). The gradient thermocycling programme was set for 40 cycles at $95{ }^{\circ} \mathrm{C}$ for $15 \mathrm{~s}, 58^{\circ} \mathrm{C}$ for $30 \mathrm{~s}$ and $72^{\circ} \mathrm{C}$ for $30 \mathrm{~s}$, with an initial cycle at $95{ }^{\circ} \mathrm{C}$ for $10 \mathrm{~min}$. During each cycle, the accumulation of PCR products was detected by monitoring the increase in fluorescence from double-stranded-DNA-binding SYBR green. Dissociation curves were run immediately after the last PCR cycle by plotting the fluorescence intensities against temperatures as the set point temperature $\left(55^{\circ} \mathrm{C}\right)$ was increased by $1{ }^{\circ} \mathrm{C}$ for $30 \mathrm{~s}$ (41 cycles). To exclude DNA contamination of RNA samples, replicate control assays were performed in which reverse transcriptase was omitted. Data were collected and analysed using the software and graphics program Mx40000 version 4.00 (Stratagene). Standard curves were obtained for both hyl and 16S rRNA genes. The relative differences in expression were analysed with the Relative Expression Software Tool (version 1.9.12) (Pfaffl et al., 2002). Each assay was performed in triplicate in three independent experiments.

Hyaluronidase activity. Measurement of hyaluronidase activity was based on the colorimetric method described by Reissig et al. (1955), slightly modified by Asteriou et al. (2001). It determines the concentration of reducing $\beta$-N-acetyl-D-glucosamine ends generated from HA hydrolysis. N-Acetyl-D-glucosamine (Sigma A 8625) was used as a standard. Briefly, bacteria from the second overnight culture were transferred to $1.5 \mathrm{ml} \mathrm{TSB}$. The supernatants from the wild-type and $\mathrm{Hyl}^{-}$mutant were collected and frozen at different time points. Prewarmed HA solution ( $200 \mu \mathrm{l}$ of $1 \mathrm{mg} \mathrm{ml}^{-1}$ solution) containing $5 \mathrm{mM}$ ammonium acetate at pH 5 was incubated with $100 \mu$ l culture supernatant at $37{ }^{\circ} \mathrm{C}$ for $1 \mathrm{~h}$. The reaction was stopped by adding $50 \mu \mathrm{l}$ borate solution, followed by vortexing and incubation in a boiling water bath for $3 \mathrm{~min}$. After cooling, $1.5 \mathrm{ml}$ of a 10 -fold diluted $p$ dimethylaminobenzaldehyde (DMAB) solution was added to each tube. In this method, the $N$-acetyl-D-glucosamine generated from degradation of HA is converted to a furan derivative, which reacts with the DMAB to form a red complex. The colour was determined spectrophotometrically at $590 \mathrm{~nm}$ after $20 \mathrm{~min}$ incubation at $37^{\circ} \mathrm{C}$. 
Each assay was performed in triplicate in three independent experiments.

Biofilm assay. Biofilm formation was assessed using the microtitre plate assay as previously described (Petersen et al., 2004). S. intermedius wild-type and $\mathrm{Hyl}^{-}$were grown in two successive overnight cultures in TSB and diluted $1: 200$ in TSB or TSB supplemented with $\mathrm{HA}\left(1 \mu \mathrm{g} \mathrm{ml}{ }^{-1}\right)$. Then $500 \mu \mathrm{l}$ aliquots were inoculated into wells of polystyrene flat-bottom 24-well microtitre plates (Nunc). The plates were incubated at $37{ }^{\circ} \mathrm{C}$ in a $5 \% \mathrm{CO}_{2}$ aerobic atmosphere for $18 \mathrm{~h}$. The biofilms were collected from some wells after $18 \mathrm{~h}$. In other wells, fresh medium with and without HA was added and biofilm formation was allowed to continue for another $18 \mathrm{~h}$. To assay biofilm detachment, biofilms formed for $18 \mathrm{~h}$ were treated with hyaluronidase (bovine testes, Sigma, $450 \mathrm{U} \mathrm{mg}^{-1}$, final concentration $225 \mathrm{U} \mathrm{ml}^{-1}$ ) for $3 \mathrm{~h}$ or $18 \mathrm{~h}$ at $37{ }^{\circ} \mathrm{C}$ in a $5 \% \mathrm{CO}_{2}$ aerobic atmosphere. The biofilms were washed twice with distilled water and suspended in $500 \mu$ fresh TSB by scraping the bottom and lateral walls of the wells with a disposable cell scraper adapted to fit into the wells. In separate wells, total growth was measured by collecting the biofilm and planktonic cells together in the $500 \mu \mathrm{l}$ medium used during incubation. To determine the amount of planktonic cells, the biofilm values were subtracted from corresponding total growth (biofilm and planktonic) values, as determined by $\mathrm{OD}_{600}$. The $\mathrm{OD}_{600}$ values of the suspended cells were measured. Each assay was performed in triplicate in three independent experiments.

The hyaluronidase activity of the wild-type was measured in a similar assay, except that $3 \mathrm{ml} 1: 200$ culture was used in each well of 6-well microtitre plates. After $18 \mathrm{~h}, 3 \mathrm{ml}$ fresh medium was added and incubated for a further $18 \mathrm{~h}$. The biofilm and planktonic cells were collected from the wells by scraping and centrifugation. The supernatant was used to assess the hyaluronidase activity. The $S$. intermedius $\mathrm{Hyl}^{-}$mutant was included as negative control and bovine hyaluronidase at different concentrations as positive control.

To evaluate the hyaluronidase activity in biofilm cells, $S$. intermedius was grown for $18 \mathrm{~h}$ in TSB medium supplemented or not with HA, as described above. Biofilm cells were collected and resuspended in TSB supplemented with $\mathrm{HA}$ and adjusted to an $\mathrm{OD}_{600}$ of 1 . The suspension was centrifuged, resuspended to a calculated $\mathrm{OD}_{600}$ of 10 and incubated at $37{ }^{\circ} \mathrm{C}$ in a $5 \% \mathrm{CO}_{2}$ aerobic atmosphere for $1 \mathrm{~h}$. The suspension was centrifuged and the supernatant was used to assay the hyaluronidase activity.

The effect of hyaluronidase treatment on biofilm formation was visualized by scanning electron microscopy. Biofilms were grown in TSB supplemented with HA as described above, except that a polystyrene disk (Nunc) was immersed in each well before inoculation. After $18 \mathrm{~h}$, biofilms were treated with hyaluronidase for $18 \mathrm{~h}$. The disks were removed, rinsed with distilled $\mathrm{H}_{2} \mathrm{O}$, and fixed with $2.5 \%$ glutaraldehyde in $0.1 \mathrm{M}$ Sørensen buffer. Dehydrated samples were obtained through a series of ethanol rinses and dried at the critical point with liquid $\mathrm{CO}_{2}$.

Hydrophobicity assay. Surface hydrophobicity of S. intermedius NCTC 11324 and the isogenic mutant was measured by the hexadecane affinity method, as described by Westergren \& Olsson (1983). Cells grown in TSB and TSB plus HA $\left(1 \mu \mathrm{g} \mathrm{ml}^{-1}\right)$ were collected at early exponential phase, washed twice with phosphatebuffered saline (PBS, Sigma), pH 7.2, and resuspended to an $\mathrm{OD}_{450}$ of 1.0. Volumes of $1.2 \mathrm{ml}$ bacterial suspensions were mixed with 200 , 250 or $300 \mu \mathrm{l}$ hexadecane. The $\mathrm{OD}_{450}$ in the aqueous phase was then measured, and the relative hydrophobicity was calculated. Each assay was performed in triplicate in three independent experiments.

Adhesion to epithelial cells. Adherence studies were performed using biotinylated bacteria and an established epithelial cell line (PE/
CA-Pj41, clone D2, European Collection of Cell Cultures, ECACC) from oral mucosa. The cells were grown in Iscove's Modified Dulbecco's Medium (Sigma) supplemented with $2 \mathrm{mM}$ glutamine (Invitrogen Life Technologies), 10\% fetal bovine serum (Invitrogen Life Technologies) and $1 \%$ penicillin-streptamycin-fungizone (PSF, Invitrogen Life Technologies). Cells were seeded in 24-well culture plates and incubated at $37{ }^{\circ} \mathrm{C}$ in $5 \% \mathrm{CO}_{2}$ to establish a confluent monolayer

Biotinylation of $S$. intermedius was performed according to the modified method described by Fallgren et al. (2001). Briefly, $S$. intermedius wild-type and $\mathrm{Hyl}^{-}$were grown for $10 \mathrm{~h}\left(\mathrm{OD}_{600} 0.800\right)$ in TSB, harvested by centrifugation (6000 r.p.m. for $10 \mathrm{~min}$ ), and washed twice with PBS, $\mathrm{pH} 7.2$. The bacterial $\mathrm{OD}_{600}$ was adjusted to approximately 1 . Equal volumes of bacteria and biotin solution (EZLink-Sulfo-NHS-LC-biotin, Pierce; $0.2 \mathrm{mg} \mathrm{ml}^{-1}$ in PBS) were incubated for $2 \mathrm{~h}$ at room temperature. The streptococcal cells were washed three times with PBS.

The confluent cells were washed twice and fixed on tissue-culture wells by incubation for $30 \mathrm{~min}$ at $37{ }^{\circ} \mathrm{C}$ with $4 \%$ glutaraldehyde in PBS, then washed twice with PBS. Uncovered plastic surfaces were blocked with $3 \%$ BSA (Sigma) in PBS for $1 \mathrm{~h}$ at $37{ }^{\circ} \mathrm{C}$. The wells were washed twice with $\mathrm{PBS}$, and $100 \mu \mathrm{l}$ biotinylated bacterial cell suspensions in PBS $\left(\mathrm{OD}_{600}\right.$ 0.7) were added to each well before incubation for $1 \mathrm{~h}$ at $37^{\circ} \mathrm{C}$. Unbound bacteria were then removed with PBS containing $0.05 \%$ Tween 20. NeutrAvidin (Pierce; $100 \mu \mathrm{l}$ of $1 / 1500$ dilution in PBS) was added to each well before further incubation for $1 \mathrm{~h}$ at $37^{\circ} \mathrm{C}$. The plates were then washed twice with PBS, and $100 \mu \mathrm{l}$ ImmunoPure TMB substrate (Boule Nordic) was added to each well. The colour was allowed to develop for $5 \mathrm{~min}$, and the reaction was stopped with $2 \mathrm{M} \mathrm{H}_{2} \mathrm{SO}_{4}$. The $A_{450}$ was measured in a Synergy HT Multi-Detection microplate reader (Biotek). Each assay was performed in triplicate in three independent experiments.

Statistical analysis. Student's $t$ test was used to analyse the data normally distributed. $P$ values of $<0.05$ were considered significant.

\section{RESULTS}

\section{Growth and expression of hyaluronidase in the presence of HA}

At stationary phase, cell density $\left(\mathrm{OD}_{600}\right)$ of the $S$. intermedius $\mathrm{Hyl}^{-}$mutant was only approximately $22 \%$ of the wild-type in MM with $\mathrm{HA}$ as sole carbohydrate source (wild-type $\mathrm{OD}_{600} 0.848$, SE $0.142 ; \mathrm{Hyl}^{-}$mutant $\mathrm{OD}_{600}$ 0.193, SE 0.097). No difference was observed between the wild-type and $\mathrm{Hyl}^{-}$in MM supplemented with glucose (data not shown). The wild-type and $\mathrm{Hyl}^{-}$had similar growth rates in TSB with or without addition of HA (data not shown).

Real-time RT-PCR was used to assess hyaluronidase gene transcription. S. intermedius hyaluronidase was upregulated in TSB supplemented with HA by a mean factor of 3.1 (SE range 1.16-8.3) compared to cells grown in the absence of HA.

Wild-type S. intermedius planktonic cells showed approximately four times more hyaluronidase activity in TSB supplemented with HA than in TSB alone (Fig. 1). The hyaluronidase accumulated during growth up to early stationary phase, whereupon the level dropped. $S$. 


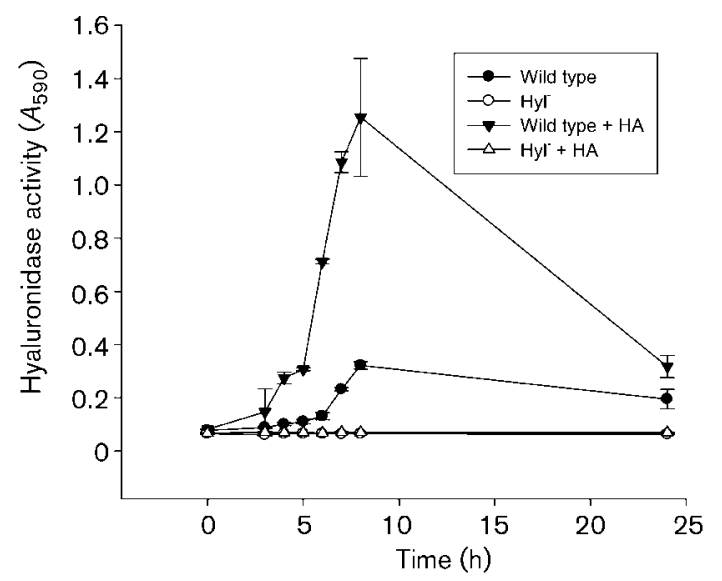

Fig. 1. Hyaluronidase activity of $S$. intermedius wild-type and $\mathrm{Hyl}^{-}$ measured during $24 \mathrm{~h}$ growth in TSB supplemented or not with HA. Hyaluronidase activity was normalized to cell number. The data are means and standard errors from three independent experiments.

intermedius $\mathrm{Hyl}^{-}$showed no hyaluronidase activity in either the presence or absence of HA (Fig. 1). It was interesting to investigate whether biofilm cells are also able to produce hyaluronidase. Measurement of hyaluronidase activity in biofilm cells after $18 \mathrm{~h}$ biofilm formation showed an activity corresponding to $351 \mathrm{U} \mathrm{ml}^{-1}$ (SE 39) in TSB supplemented with HA and $123 \mathrm{U} \mathrm{ml}^{-1}$ (SE 28) in TSB not supplemented with HA; the differences were statistically significant.

\section{Hyaluronidase promotes biofilm cell detachment and disaggregation}

The possible involvement of hyaluronidase and HA in biofilm formation by $S$. intermedius was investigated using the microtitre plate assay and culture media supplemented or not with HA. In TSB supplemented with HA the $\mathrm{Hyl}^{-}$ mutant formed $31 \%$ more biofilm after $36 \mathrm{~h}$ than the wild-type. In non-supplemented TSB a non-significant reduction was observed in the wild-type compared to the $\mathrm{Hyl}^{-}$mutant (data not shown). Total growth, assessed as the sum of planktonic and biofilm cells, was not significantly different in any case (Fig. 2). Treatment of biofilms for $16 \mathrm{~h}$ with hyaluronidase reduced the biofilm mass by about $66 \%$, concomitant with $48 \%$ increase in the planktonic fraction (Fig. 2). Hyaluronidase added at the time of inoculation reduced the $S$. intermedius wild-type and $\mathrm{Hyl}^{-}$biofilm formation to almost the same levels as those observed with hyaluronidase added after $18 \mathrm{~h}$ (data not shown). Hyaluronidase treatment of established biofilms for $3 \mathrm{~h}$ had no significant effect on the biofilm mass (data not shown). Measurement of the hyaluronidase activity in the wells of the wild-type showed an activity of $270 \mathrm{U} \mathrm{ml}^{-1}$ (SE 10), a value approximately the same as the amount added in the hyaluronidase detachment assay. We used scanning electron microscopy to detect possible

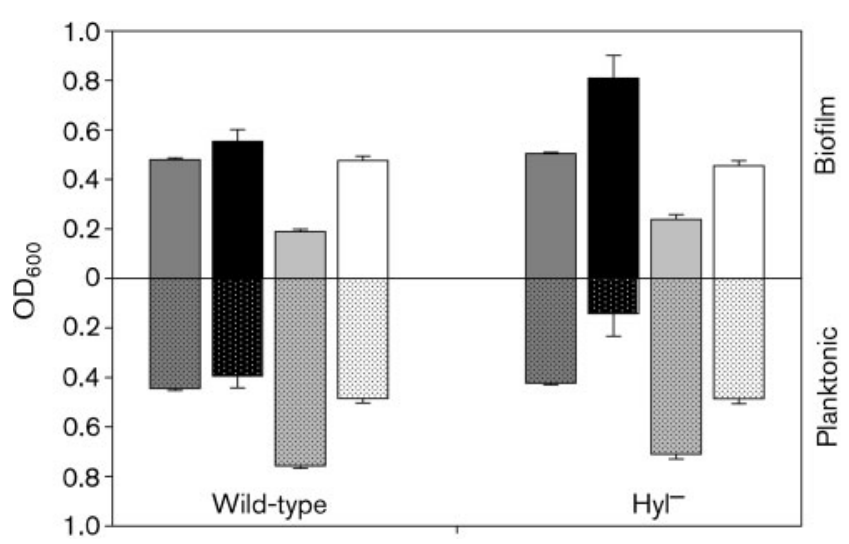

Fig. 2. Growth of $S$. intermedius wild-type and $\mathrm{Hyl}^{-}$in TSB supplemented with HA. Cell density of biofilm (solid bars) and planktonic cells (speckled bars) in the wells after $18 \mathrm{~h}$ (initial biofilm, dark grey bars), $36 \mathrm{~h}$ without hyaluronidase treatment (initial biofilm plus $18 \mathrm{~h}$ incubation, black bars) and $36 \mathrm{~h}$ with hyaluronidase treatment (initial biofilm plus $18 \mathrm{~h}$ with hyaluronidase treatment, light grey bars) monitored as $\mathrm{OD}_{600}$. Control wells not supplemented with HA and hyaluronidase were included (open bars). Biofilm cells were washed and resuspended to the same volume as the planktonic cells. The results are means and standard errors from three independent experiments.

alterations in biofilm architecture by hyaluronidase treatment. Wild-type $S$. intermedius formed very dense biofilms in TSB medium supplemented with HA. When the biofilm was treated with hyaluronidase only a thin layer of cells remained attached to the surface (Fig. 3).

\section{Expression of hyaluronidase does not influence cell-surface hydrophobicity}

Since hyaluronidase may be cell-bound through the anchor domain containing the LPXTG motif, we determined whether inactivation of $h y l$ altered cell hydrophobicity compared to the wild-type when grown in TSB supplemented or not with HA. Cell hydrophobicity was determined by adsorption to hexadecane and calculated as the percentage loss in $\mathrm{OD}_{450}$ relative to that of the initial bacterial suspension. Inactivation of the hyaluronidaseencoding gene in S. intermedius resulted in no significant differences in hydrophobicity compared to the wild-type at early exponential phase irrespective of HA supplementation or not (unsupplemented medium: wild-type 39\%, SE 1.49 and $\mathrm{Hyl}^{-} 33 \%$, SE 1.62; HA-supplemented medium: wild-type: $36 \%$, SE 0.66 and $\mathrm{Hyl}^{-}: 37 \%$, SE 0.29 ).

\section{Inactivation of hyl does not affect adherence of S. intermedius to epithelial cells.}

We hypothesized that hyaluronidase could act as an adhesin and mediate binding of $S$. intermedius to epithelial cells. For this purpose we compared the wild-type and 

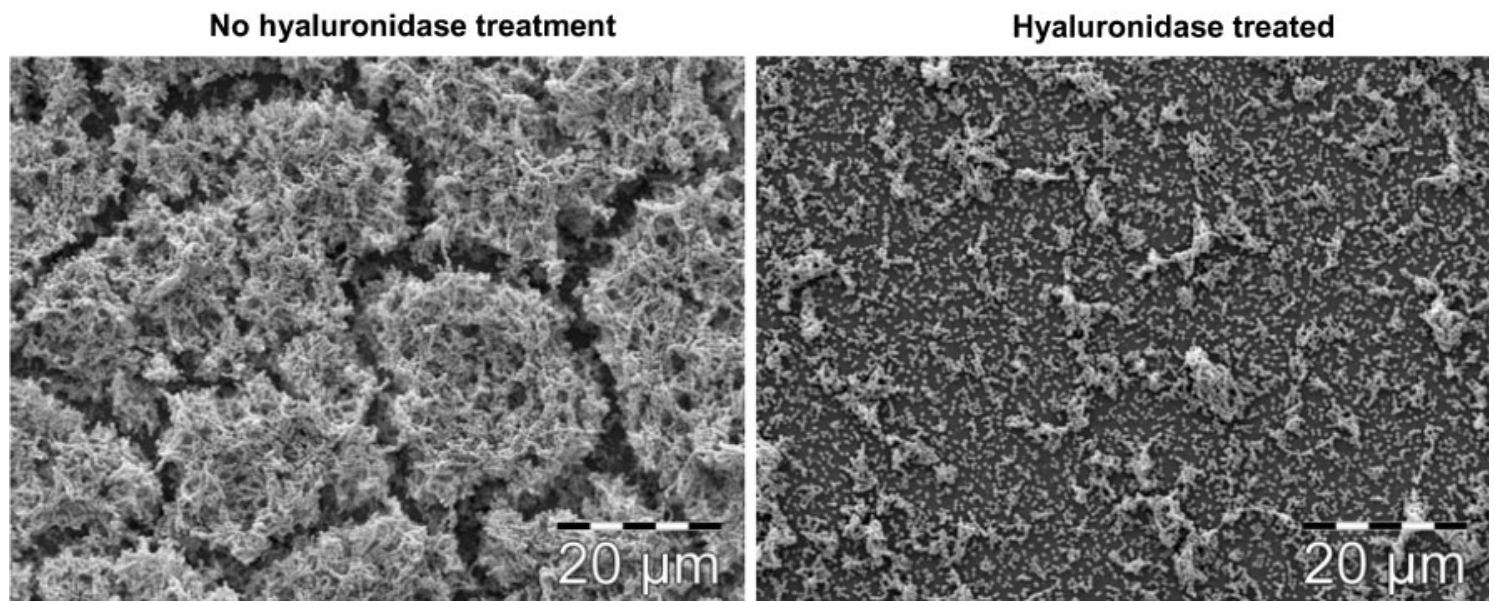

Fig. 3. Scanning electron microscopy of $S$. intermedius wild-type biofilms grown for $36 \mathrm{~h}$ in TSB supplemented with HA, not treated (left picture) or treated with hyaluronidase for $18 \mathrm{~h}$ (right picture). Scale bars, $20 \mu \mathrm{m}$.

$\mathrm{Hyl}^{-}$mutant. Adhesion of $\mathrm{Hyl}^{-}$was similar to the wildtype, suggesting that hyaluronidase is not directly involved in adhesion of S. intermedius to epithelial cells.

\section{DISCUSSION}

In this study addition of HA to the growth media was an attempt to create a simple model reflecting the importance of HA and hyaluronidase in S. intermedius colonization. Both HA and hyaluronidase influenced S. intermedius biofilm formation, while total growth remained constant and similar in the wild-type and $\mathrm{Hyl}^{-}$. Interestingly, we found that despite lacking hyaluronidase the $\mathrm{Hyl}^{-}$mutant formed more biofilm than the wild-type strain in TSB supplemented with HA. It seems therefore that hyaluronidase does not act as an adhesin to promote biofilm formation. Hydrophobic interactions with surfaces have been shown to be involved in adhesion, which is the first step of biofilm formation. Similar hydrophobic interactions were found in the wild-type and $\mathrm{Hyl}^{-}$mutant, indicating that hyaluronidase may not be involved in intial adhesion and subsequent biofilm formation.

It has been shown that polysaccharide-degrading enzymes of microbial or phage origin may cause localized destructions, with possible weakening of the biofilm community structure and subsequent loss of both cells and macromolecules (Sutherland, 2001). Recently, the oral pathogen Actinobacillus actinomycetemcomitans was shown to secret a hydrolytic enzyme that cleaves poly- $\beta-1,6-N$-acetyl-Dglucosamine, a polysaccharide adhesin of diverse species, leading to biofilm dispersal (Itoh et al., 2005; Kaplan et al., 2003). We suggest that hyaluronidase could act similarly, breaking down adhesins or extracellular matrix of $S$. intermedius biofilm and thus promote detachment. Supporting this possibility, we found that exposure of HA-grown biofilms to hyaluronidase for $18 \mathrm{~h}$ strongly reduced the biofilm mass. These results, which were confirmed by scanning electron microscopy, indicate that HA formed part of the extracellular structure of the biofilm. It is well known that the composition of biofilms is influenced by the types of nutrients in the environment (Bowden \& Li, 1997). In group A streptococci several genes are differentially expressed in HA-enriched media (Zhang et al., 2007). We cannot exclude, therefore, that the ability of $S$. intermedius to hydrolyse HA may influence expression of factors positively or negatively associated with biofilm formation.

We studied the possible involvement of S. intermedius hyaluronidase in adhesion to epithelial cells, since attachment to epithelial cells may be an initial event in periodontal infection. The S. intermedius hyaluronidase could presumably be involved in bacterial adhesion in two ways: by functioning as an adhesin or by degrading the HA cell-surface coatings, thereby allowing direct contact between the bacterium and specific receptors on the cell surface (King et al., 2004). Our data do not support such functions since no difference was found between the $\mathrm{Hyl}^{-}$ strain and the wild-type as to adhesion to epithelial cells. However, we have not investigated whether the epithelial cells used in this study actually produce HA. The present model might differ from conditions observed in sites in which exogenous HA (e.g. from saliva) may be present.

S. intermedius wild-type was able to utilize HA as a sole carbon source. The $\mathrm{Hyl}^{-}$mutant on the other hand was incapable of using HA as energy source. In the oral cavity, the gingival crevice shows $28.2 \mathrm{mg} \mathrm{HA} \mathrm{ml}^{-1}$ (Smith et al., 1995), against $0.46 \mathrm{mg} \mathrm{ml}^{-1}$ in whole unstimulated saliva (Pogrel et al., 1996). The higher concentration of HA in the gingival crevice may be an important ecological factor in $S$. intermedius distribution around the margins of the teeth. We showed by real-time RT-PCR that hyaluronidase is upregulated in TSB supplemented with HA. The results 
were confirmed by biochemical methods. The ability to sense the environment and mount an appropriate adaptive transcriptional response may be of crucial importance for $S$. intermedius colonization and pathogenicity.

The establishment of biofilms by bacteria protects them from host defences and antibiotics. Biofilm formation is a dynamic process which involves initial attachment of cells to the surface, production of extracellular polymers, maturation, and dispersion of single cells from the biofilm. Approaches to combat biofilms may be to promote biofilm dispersal. We showed in the present study that hyaluronidase promotes $S$. intermedius detachment. It is possible that $S$. intermedius secretes hyaluronidase to detach from the surface or from other bacteria in an attempt to colonize other tissues. A better understanding of the mechanisms involved in S. intermedius biofilm disruption by hyaluronidase could lead to improved strategies for treatment and prevention of diseases caused by this bacterium.

\section{ACKNOWLEDGEMENTS}

We thank Camilla Husvik for assistance with the cell culture and Steinar Stølen for help with scanning electron microscopy.

\section{REFERENCES}

Agren, U. M., Tammi, M., Ryynanen, M. \& Tammi, R. (1997). Developmentally programmed expression of hyaluronan in human skin and its appendages. J Invest Dermatol 109, 219-224.

Aoki, K., Matsumoto, S., Hirayama, Y., Wada, T., Ozeki, Y., Niki, M., Domenech, P., Umemori, K., Yamamoto, S. \& other authors (2004). Extracellular mycobacterial DNA-binding protein 1 participates in mycobacterium-lung epithelial cell interaction through hyaluronic acid. J Biol Chem 279, 39798-39806.

Asteriou, T., Deschrevel, B., Delpech, B., Bertrand, P., Bultelle, F., Merai, C. \& Vincent, J. C. (2001). An improved assay for the $\mathrm{N}$-acetylD-glucosamine reducing ends of polysaccharides in the presence of proteins. Anal Biochem 293, 53-59.

Bowden, G. H. \& Li, Y. H. (1997). Nutritional influences on biofilm development. Adv Dent Res 11, 81-99.

Branda, S. S., Vik, S., Friedman, L. \& Kolter, R. (2005). Biofilms: the matrix revisited. Trends Microbiol 13, 20-26.

Camenisch, T. D., Spicer, A. P., Brehm-Gibson, T., Biesterfeldt, J., Augustine, M. L., Calabro, A., Jr, Kubalak, S., Klewer, S. E. \& McDonald, J. A. (2000). Disruption of hyaluronan synthase-2 abrogates normal cardiac morphogenesis and hyaluronan-mediated transformation of epithelium to mesenchyme. J Clin Invest 106, 349-360.

Claridge, J. E., III, Attorri, S., Musher, D. M., Hebert, J. \& Dunbar, S. (2001). Streptococcus intermedius, Streptococcus constellatus, and Streptococcus anginosus ("Streptococcus milleri group") are of different clinical importance and are not equally associated with abscess. Clin Infect Dis 32, 1511-1515.

Costerton, J. W., Lewandowski, Z., Caldwell, D. E., Korber, D. R. \& Lappin-Scott, H. M. (1995). Microbial biofilms. Annu Rev Microbiol 49, 711-745.

Costerton, J. W., Stewart, P. S. \& Greenberg, E. P. (1999). Bacterial biofilms: a common cause of persistent infections. Science 284, 1318-1322.
Fallgren, C., Andersson, A. \& Ljungh, A. (2001). The role of glycosaminoglycan binding of staphylococci in attachment to eukaryotic host cells. Curr Microbiol 43, 57-63.

Feldman, C., Cockeran, R., Jedrzejas, M. J., Mitchell, T. J. \& Anderson, R. (2007). Hyaluronidase augments pneumolysin-mediated injury to human ciliated epithelium. Int J Infect Dis 11, 11-15.

Girish, K. S. \& Kemparaju, K. (2007). The magic glue hyaluronan and its eraser hyaluronidase: a biological overview. Life Sci 80, 1921-1943.

Gossling, J. (1988). Occurrence and pathogenicity of the Streptococcus milleri group. Rev Infect Dis 10, 257-285.

Hamada, S. \& Slade, H. D. (1980). Biology, immunology, and cariogenicity of Streptococcus mutans. Microbiol Rev 44, 331-384.

Hashioka, K., Suzuki, K., Yoshida, T., Nakane, A., Horiba, N. \& Nakamura, H. (1994). Relationship between clinical symptoms and enzyme-producing bacteria isolated from infected root canals. J Endod 20, 75-77.

Homer, K., Shain, H. \& Beighton, D. (1997). The role of hyaluronidase in growth of Streptococcus intermedius on hyaluronate. Adv Exp Med Biol 418, 681-683.

Homer, K. A., Roberts, G., Byers, H. L., Tarelli, E., Whiley, R. A., Philpott-Howard, J. \& Beighton, D. (2001). Mannosidase production by viridans group streptococci. J Clin Microbiol 39, 995-1001.

Hynes, W. L. \& Walton, S. L. (2000). Hyaluronidases of Gram-positive bacteria. FEMS Microbiol Lett 183, 201-207.

Itoh, Y., Wang, X., Hinnebusch, B. J., Preston, J. F., III \& Romeo, T. (2005). Depolymerization of $\beta$-1,6-N-acetyl-D-glucosamine disrupts the integrity of diverse bacterial biofilms. J Bacteriol 187, 382-387.

Kaplan, J. B., Ragunath, C., Ramasubbu, N. \& Fine, D. H. (2003). Detachment of Actinobacillus actinomycetemcomitans biofilm cells by an endogenous $\beta$-hexosaminidase activity. J Bacteriol 185, 4693-4698.

King, S. J., Allen, A. G., Maskell, D. J., Dowson, C. G. \& Whatmore, A. M. (2004). Distribution, genetic diversity, and variable expression of the gene encoding hyaluronate lyase within the Streptococcus suis population. J Bacteriol 186, 4740-4747.

Last, K. S. \& Embery, G. (1987). Hyaluronic acid and hyaluronidase activity in gingival exudate from sites of acute ulcerative gingivitis in man. Arch Oral Biol 32, 811-815.

Nyberg, A., Engstrom-Laurent, A. \& Loof, L. (1988). Serum hyaluronate in primary biliary cirrhosis - a biochemical marker for progressive liver damage. Hepatology 8, 142-146.

Okayama, H., Nagata, E., Ito, H. O., Oho, T. \& Inoue, M. (2005). Experimental abscess formation caused by human dental plaque. Microbiol Immunol 49, 399-405.

Petersen, F. C., Pasco, S., Ogier, J., Klein, J. P., Assev, S. \& Scheie, A. A. (2001). Expression and functional properties of the Streptococcus intermedius surface protein antigen I/II. Infect Immun 69, 4647-4653.

Petersen, F. C., Pecharki, D. \& Scheie, A. A. (2004). Biofilm mode of growth of Streptococcus intermedius favored by a competencestimulating signaling peptide. J Bacteriol 186, 6327-6331.

Pfaffl, M. W., Horgan, G. W. \& Dempfle, L. (2002). Relative expression software tool (REST) for group-wise comparison and statistical analysis of relative expression results in real-time PCR. Nucleic Acids Res 30, e36.

Piscitelli, S. C., Shwed, J., Schreckenberger, P. \& Danziger, L. H. (1992). Streptococcus milleri group: renewed interest in an elusive pathogen. Eur J Clin Microbiol Infect Dis 11, 491-498.

Pogrel, M. A., Lowe, M. A. \& Stern, R. (1996). Hyaluronan (hyaluronic acid) in human saliva. Arch Oral Biol 41, 667-671.

Reissig, J. L., Storminger, J. L. \& Leloir, L. F. (1955). A modified colorimetric method for the estimation of $\mathrm{N}$-acetylamino sugars. J Biol Chem 217, 959-966. 
Rovelstad, G. H., Geller, J. H. \& Cohen, A. H. (1958). The hyaluronidase activity of saliva. II. The relationship of hyaluronidase activity to dental caries experience, gingivitis, and oral hygiene in young male adults. J Dent Res 37, 114-118.

Ruoslahti, E. (1996). Brain extracellular matrix. Glycobiology 6, 489-492.

Shain, H., Homer, K. A. \& Beighton, D. (1996). Purification and properties of a novel glycosaminoglycan depolymerase from Streptococcus intermedius strain UNS 35. J Med Microbiol 44, 381-389.

Smith, A. J., Addy, M. \& Embery, G. (1995). Gingival crevicular fluid glycosaminoglycan levels in patients with chronic adult periodontitis. J Clin Periodontol 22, 355-361.

Starr, C. R. \& Engleberg, N. C. (2006). Role of hyaluronidase in subcutaneous spread and growth of group A streptococcus. Infect Immun 74, 40-48.

Sutherland, I. W. (2001). The biofilm matrix - an immobilized but dynamic microbial environment. Trends Microbiol 9, 222-227.

Tao, L., LeBlanc, D. J. \& Ferretti, J. J. (1992). Novel streptococcalintegration shuttle vectors for gene cloning and inactivation. Gene 120, 105-110.

Takao, A. (2003). Cloning and expression of hyaluronate lyase genes of Streptococcus intermedius and Streptococcus constellatus subsp. constellatus. FEMS Microbiol Lett 219, 143-150.

Takao, A., Nagashima, H., Usui, H., Sasaki, F., Maeda, N., Ishibashi, K. \& Fujita, H. (1997). Hyaluronidase activity in human pus from which Streptococcus intermedius was isolated. Microbiol Immunol 41, 795-798.
Tammi, R., Tammi, M., Hakkinen, L. \& Larjava, H. (1990). Histochemical localization of hyaluronate in human oral epithelium using a specific hyaluronate-binding probe. Arch Oral Biol 35, 219-224.

Tammi, M. I., Day, A. J. \& Turley, E. A. (2002). Hyaluronan and homeostasis: a balancing act. J Biol Chem 277, 4581-4584.

Tanner, A., Maiden, M. F., Lee, K., Shulman, L. B. \& Weber, H. P. (1997). Dental implant infections. Clin Infect Dis 25 (Suppl 2), S213-S217.

Unsworth, P. F. (1989). Hyaluronidase production in Streptococcus milleri in relation to infection. J Clin Pathol 42, 506-510.

Westergren, G. \& Olsson, J. (1983). Hydrophobicity and adherence of oral streptococci after repeated subculture in vitro. Infect Immun 40, 432-435.

Whiley, R. A., Beighton, D., Winstanley, T. G., Fraser, H. Y. \& Hardie, J. M. (1992). Streptococcus intermedius, Streptococcus constellatus, and Streptococcus anginosus (the Streptococcus milleri group): association with different body sites and clinical infections. J Clin Microbiol 30, 243-244.

Zhang, M., McDonald, F. M., Sturrock, S. S., Charnock, S. J., Humphery-Smith, I. \& Black, G. W. (2007). Group A streptococcus cell-associated pathogenic proteins as revealed by growth in hyaluronic acid-enriched media. Proteomics 7, 1379-1390.

Edited by: T. Msadek 